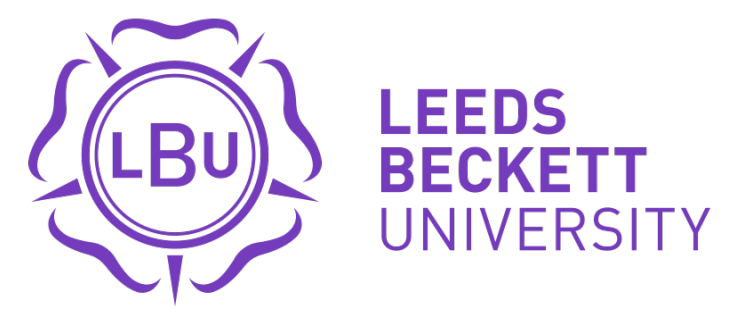

Citation:

Wilkinson, C (2018) Implementing a cross-curricular digital project into a PGCE computer science initial teacher education course. In: 2017 Intelligent Systems Conference (IntelliSys). IEEE, pp. 751-756. ISBN 978-1-5090-6436-6, 978-1-5090-6435-9 DOI: https://doi.org/10.1109/IntelliSys.2017.8324213

Link to Leeds Beckett Repository record:

https://eprints.leedsbeckett.ac.uk/id/eprint/4103/

Document Version:

Book Section (Published Version)

Conference proceeding

The aim of the Leeds Beckett Repository is to provide open access to our research, as required by funder policies and permitted by publishers and copyright law.

The Leeds Beckett repository holds a wide range of publications, each of which has been checked for copyright and the relevant embargo period has been applied by the Research Services team.

We operate on a standard take-down policy. If you are the author or publisher of an output and you would like it removed from the repository, please contact us and we will investigate on a case-by-case basis.

Each thesis in the repository has been cleared where necessary by the author for third party copyright. If you would like a thesis to be removed from the repository or believe there is an issue with copyright, please contact us on openaccess@leedsbeckett.ac.uk and we will investigate on a case-by-case basis. 


\section{Implementing a cross-curricular digital project into a PGCE Computer Science Initial Teacher Education course}

\author{
Dr Carl Wilkinson) \\ School of Education
}

\author{
Leeds Beckett University \\ Leeds, UK \\ Carl.Wilkinson@leedsbeckett.ac.uk
}

\begin{abstract}
The aim of this research is to open discourse over the matters, processes and skills of the subject of Computer Science in the new English National Curriculum of 2013. The challenge for graduate computer scientists enrolled onto a Post Graduate Certificate of Education Initial Teacher Training course in the North of England was to develop a cross-curricular digital technology project using Raspberry $\mathrm{Pi}$ hardware and peripherals that could sense and record data to enhance pedagogy in any other English National Curriculum subject. The results of the research were unexpected and highlight the need for 'soft skill' development within the Computer Science curriculum.
\end{abstract}

Keywords-Computer Science, soft skills, computational skills, Raspberry Pi, English National Curriculum, Initial Teacher training, Initial Teacher Education, problem solving.

\section{INTRODUCTION}

The English National Curriculum was revised in 2013 and part of the revision replaced the subject of Information and Computer Technology (ICT) with the new subject of Computer Science. Michael Gove, the Secretary of Education at the time deemed ICT not fit for purpose. Recruitment into Initial Teacher Education (ITE) reflects the change and graduates onto Post Graduate Certificate of Education (PGCE) courses need to have studied computer technology and have programming experience. Notwithstanding the technical expertise anticipated in rudimentary technology, it would be expected that graduates with this background would have developed their 'soft skills' sufficiently to be able to initiate simple projects with unfamiliar hardware and software and to be able to communicate and negotiate with other graduates to develop a collaborative digital project that would enhance pedagogy of both subject specialisms, as would possibly be expected in the real world, where computer experts might work with non-specialists to solve problems. The transference of graduate studies into a real project would test the trainees all round ability in a secure environment without children and enable practise of computational thinking which would draw upon National Curriculum (NC) requirements and social interaction. The intentions of this research project, fully expected a successful outcome, however, it was evident very early in the project that this was not going to be so straight forward and so the question arose, why not? The study considers quantitative evidence, collected during and after the project to determine what went wrong, in order to inform future projects and also reflect on a wider meta-cognitive question as to the importance of 'softskills' or computational thinking as described in the literature that follows.

\section{LITERATURE}

There is a recognised teaching and learning difference between Digital Technology (DT) and Computer Science (CS), wherein the former can be classified as pedagogy for the use and understanding of technology that processes digital signals, whether or not it contains a micro-processor in which case it may require programming and the latter pertaining to pedagogy relating to programmable micro-processor based devices only. The English National Curriculum for Computing [1] stipulates as a purpose of study;

'The core of computing is computer science, in which pupils are taught the principles of information and computation, how digital systems work, and how to put this knowledge to use through programming'... through subject content such as;

- 'undertake creative projects that involve selection, using, and combining multiple applications, preferably across a range of devices, to achieve challenging goals, including collecting and analysing data and meeting the needs of known users

- Create, re-use, revise and re-purpose digital artefacts for a given audience, with attention to trustworthiness, design and usability' [1].

\section{A. Computational thinking and soft-skills support}

CS through Computational Thinking (CT) has a large development base with regards to Problem Solving (PS) and empirical evidence is offered for the inclusion of CS in a national curriculum with regards to this history of soft-skill development. EduSummit 2015 [2] indicated that CT was generally accepted within a CS curriculum and could be accessed throughout a national curriculum more broadly. However, what if these so called soft-skills have not been sufficiently practised and the expectations are that it would have been for Initial Teacher Trainees (ITT) who have a 
background in CS and have a related CS Degree? Ahmed et al. [3] considered the nurturing effect of mediational and motivational emotional development in early adolescents through their perceived social support (PSS). They found that social support positively affected the participant's achievement through motivational perception which reduced emotional anxiety. Gee [4] noted that young children learn better through social interaction through action and talking with others. Tang and Tan [5] noted that school administrators are critical of novice teacher's lack of soft skills, inclusive of critical thinking and problem solving. Ulusoy et al. [6] considered the need for ITT's to perceive themselves positively in problem solving skills. Erdamar and Alpan [7] recognised the epistemological beliefs and problem solving skills changed during the process of teaching practice. A cross-cultural study of concepts in CS education by Zendler et al. [8] comparing professorial analysis of two nations' CS curriculum indicated that although different in focus, i.e. one being more technical compared to the other being more soft-skill focus, both were analysed to be comparable. Regardless of whether the programmes of study relate to recognised CS study, i.e. algorithm, communication, computation etc. as the German curriculum does or analysing, categorising, classifying, etc. for the United States curriculum, the professors agreed that both curricula covered the subject sufficiently. However, although there are numerous taxonomies proposed by individual CS figures (ibid.), notwithstanding, the question still arises as to the purpose of a CS curriculum. Is it meant to be a standalone subject to introduce children to all what is known and good about CS, or is it to prepare children for the world of working in a technological age?

\section{B. Problem solving and motivation}

Problem Solving (PS) is considered a soft skill because it cannot be easily tied down as a concept, it is dependent on many uncoordinated rituals that can be experienced over time, but the ability to problem solve in any arena requires a sound subject knowledge. Using that knowledge in a context based problem is a real test of understanding wherein subject knowledge could be considered to be mastered if successfully solved. However, there are other constraining factors to consider, which could prohibit PS ability at any one time. Turer [9] indicated that there must be a desire to fulfil a need emanating from the PS solution by participants. Arslan [10] found that a negative relationship towards PS could occur with poor communication skills, coupled with a lack of self-confidence which could negate a persistent persevering approach required to solve problems. On the other hand, Karami et al. [11] found that a significant enhancement was made to ITT's subject knowledge when they employed problem based learning in their practice. Procedural thinking, as developed by Papert [12] and [13] in the study of LOGO, is considered to be beneficially developed through allowing students time to manipulate and experiment with digital technology.

\section{Cross-curricular collaboration in English schools}

Cross-curricular practice in schools is sporadic, many ITT's report that they have been involved or witnessed little crosscurricular activity while on teaching practice. This is confirmed in the Jarvinen and Rasinen [14] study of the 'Human being and technology' strand of the Finnish national curriculum. In order to make CS programming accessible to children software has been developed which reduces the syntactic complexity, such as 'Scratch', but Fincher [15] argues that this can cause misunderstanding later on, when students follow a more rigorous coding curricula. However, reducing the complexity of coding allows non experts to access the technology, specifically for cross-curricular purposes and at Primary school, where teachers are not subject specific. A study by Unlu and Dokme [16] reported that $7^{\text {th }}$ grade students enjoyed Science lessons more when digital technology was utilised, for this to happen the science teacher must be able to use the technology easily without the need for dedicated subject knowledge in CS. Cerf [17] proposes that the use of DT in other subjects than CS enables practical and social participation. However, the reality is that similar to the viewpoint of Franklin [18] calling for more cooperation between education and CS departments in Higher Educational Institutions (HEI), in order to create more research evidence, the same chasm appears in schools, wherein very little cross-collaboration occurs, other than the occasional use of simplified topic or theme based learning.

\section{Summary}

There is no doubt that a graduate with a CS degree would have sufficient subject knowledge to teach CS in English Secondary schools. However, CT and soft-skills are crucial for PS and a focus on coding, which is eminent in English schools, does not practise true PS sufficiently. The programming languages utilised in English schools have simplified syntax in order to make coding more accessible for children and non-specialists, but cross-collaboration, a key to producing real life scenarios, is negligible unless practioners are motivated and have sufficient soft- skills to do so. This research set out to test these skills in a safe environment. The CS ITT's were tasked with developing a cross-collaboration project using digital technology and the findings highlight the need to develop softskills throughout the CS educational structure.

\section{METHOD}

The two CS ITT's participating in the project both had CS Degree qualifications, one had previous industrial experience and the other experience of working in Secondary schools. The non-subject specialists in CS available to the two CS trainees included trainees with specialisms in Physical Education (PE), Art and Design (A\&D), Physics, Mathematics, English, Religious Education (RE), Geography, Music and Design and Technology (D\&T), in no specific order. During subject specialism training the CS trainees had some of their sessions 
in a Science Technology Engineering Mathematics (STEM) cohort and part solely CS. For general professional studies, part of their studies was as a whole group, 76 trainees, part in mixed classes of approximately 25 trainees and part in mixed groups of four and their Masters' studies had a variety of mixed options. So, there was plenty of opportunity to collaborate with alternative subject specialists. This was important because the set task for the CS trainees was to develop a cross-curricular digital technology project that could satisfy a need in another subject, so not only did they have nine other subjects to choose from, but they had been provided with experiences which led them to collaborate. They were allocated four three hour afternoon sessions, over a period of four weeks, to carry out the task, during which they needed to familiarise themselves with the technology, draw up some initial plans for collaboration, make contact with another subject specialist, carry out the test and evaluate their findings. The CS trainees had access to personal computers and technical support, but they were encouraged to try to solve the whole project themselves, as is expected by practising teachers in any school.
The sensors provided for the experiment include sufficient devices that could be utilised for any scenario in any of the subject specialisms listed above, with imagination and innovation. After becoming familiar with the hardware, the CS ITT's needed to make contact with a non-specialist from another subject, introduce the project and design a suitable collaboration. Followed by building and testing the device and demonstration to the non-specialist.

The research data in the study is qualitative and was collected from individual interviews with the two participants and notes made during the project. The interview consisted of a structured questionnaire, each question was asked in turn and the researcher scribed the participant's response. The trainees were interviewed separately, but their responses have been merged together for reporting purposes and to maintain anonymity. Although the participation is small, it contains evidence that can contribute to the discussion about the content and direction of the English National Curriculum for Computer Science and provides further empirical evidence of the need for soft-skill development in CS courses in order to practise PS.

The equipment included;

Raspberry Pi (Figure 1)

Top hat (Figure 1)

Sensors (Figure 2 and 3).

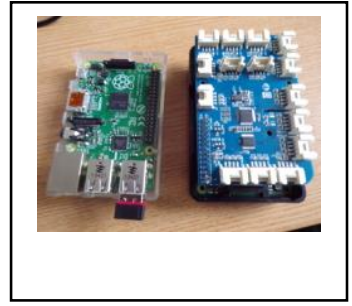

Fig. 1. Raspberry Pi and with TOPHAT fitted

The sensors included;

\begin{tabular}{|c|}
\hline 125KHz RFID Reader \\
2 Coil Latching Relay \\
3-Axis Digital Accelerometer $( \pm 1.5 \mathrm{~g})$ \\
3-Axis Digital Compass \\
3-Axis Digital Gyro \\
80cm Infrared Proximity \\
Air Quality \\
Alcohol \\
Barometer \\
Blue LED \\
Button \\
Buzzer \\
\hline
\end{tabular}

\begin{tabular}{|c|}
\hline Dry-Reed Relay \\
Dust \\
Electricity \\
Electromagnet \\
Flame \\
Gas (MQ2) \\
Gas (MQ5) \\
Gas (MQ9) \\
Gesture \\
GPS \\
Green LED \\
HCHO \\
\hline
\end{tabular}

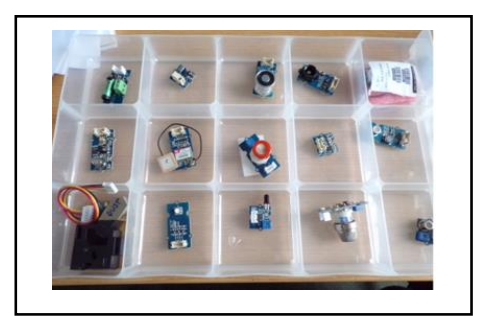

Fig. 2. Range of Grove sensors

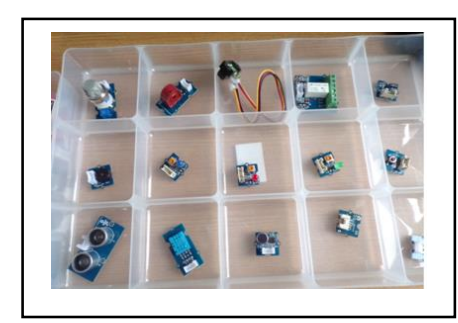

Fig. 3. Additional Grove sensors

A Raspberry Pi is a single circuit board computer costing less than $£ 40$ in England. Peripherals can be added, such as screen, keyboard etc. so that it can be used as a computer. Further input and output devices can be connected through the use of a TOPHAT, which is connected on top of the Raspberry Pi and allows Hardware to be Attached on Top. Raspberry Pi's are very commonly used in English schools because of its low cost, ease of use and back up support.

\begin{tabular}{|c|}
\hline Heart Rate (Finger clip) \\
I2C Colour Sensor \\
LCD RGB Backlight \\
Light \\
Red LED \\
Relay \\
Rotary Angle \\
Sound \\
Temperature and Humidity \\
Ultrasonic Ranger \\
\end{tabular}




\section{FINDINGS}

\section{A. The project}

The following findings are drawn from observation and discussion with the trainees, their project evaluations and an individual interview comprising of set questions, on completion of the project. There was no assessment of the project as far as trainees grades were concerned, but they were aware that their performance was being monitored which could feed discussion on their subject and professional needs audit.

The project got off to a stalled start, because within one hour of setting the task, the trainees disclosed that the project was too hard and they didn't feel competent enough to carry it out. After a lengthy talk with regards to problem solving and the need for resilience and patience, they agreed to restart and make an attempt. Technical issues with software drivers were encountered, but with help from the technical support, the trainees were able to overcome these and begin to practise developing their understanding of using the Raspberry Pi and coding using the common programmes Scratch and Python, preloaded into the hardware, programs which are also commonly found in use in schools. The next insurmountable barrier experienced by the trainees was attaining a suitable collaborator. They found it difficult to communicate successfully to their fellow trainees of other subjects convincingly enough to strike up collaboration. So, although they had thought of a number of projects to suit different crosscurricular needs, they couldn't actually convince anyone to join them. After a number of announcements made on their behalf via the virtual learning environment and still no takers, a suitable physicist trainee was recruited for them, who it was noticed, had a particular flair for using digital technology in their own micro-lesson practise. When collaboration had been sort, the trainees proceeded to develop a project with scientific content with the physicist to mutually create a project which could be used in a biology lesson.

The project entailed a bleep test/reaction game while monitoring contestant's pulse rate, Figure 4.

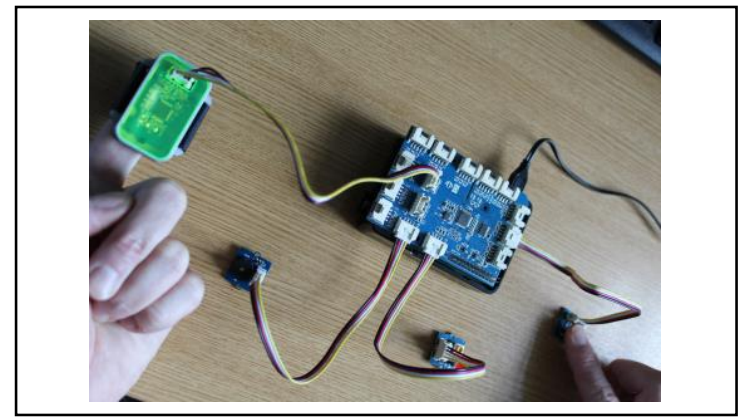

Fig. 4 TOPHAT, pulse sensor, push switch, buzzer and LED connected to Raspberry Pi

The programme records reaction time to a buzz or LED while also monitoring pulse rate. The data collected could be compared to analyse whether there is a correlation between heart rate stress and reaction time, a reasonable biology lesson utilising digital technology in the school laboratory, not entirely uncommon in schools. As all science teachers in England, regardless of specialism need to be able to teach general science at Key Stage 3, this project had validity in English schools.

\section{B. Responses to questionnaire}

Question 1 - Have you used raspberry Pi before and if not how difficult was it to familiarise yourself with it and be in a position to develop a sensing device?

No. A lot harder than it could have been. Didn't know what we were doing. First session learnt Python, then learnt how to operate outputs. Took time to work, but discovered a driver was missing. Once right drivers in place, it is relatively easy to install requirements.

Never. Fairly easy, similar to do things. There was a problem, because it was missing drivers to work to Python. Grove was great, book easy to understand. Separate sensors did not have instructions, they were complicated - some worked and some didn't. Maybe a different brand might help - one with clearer instructions

Question 2 - What were the factors influencing your choice of sensing and the cross-curricular subject?

Time was the biggest factor. Lack of experience with Pi. Had to learn how to program, would have been a lot quicker otherwise. Time limited use. Only limited amount of sensors, but can see how to adapt to work with other sensing devices.

Too overambitious. Had big ideas, but needed to limit, because of lack of experience and the sensors limited us. Could get Physics in immediately, but couldn't get PE. Said they didn't have time, too much to do.

Question 3 - What were the development benefits and restrictions of doing this project?

Benefit - Raspberry Pi, confidence in Python. Know that this is used in schools where we will be training. Had a play with Scratch.

Restrictions - time allowed and available sensors. Grove kit limited. Could be expanded though, e.g. instead of LED could use relay to power other things, but that's getting into electronics.

Restrictions - some of it didn't work and set up wasn't right. Lack of practise with Python, got used to using it and became familiar with common problems. Probably the most time for teachers in classroom is solving common problems, experience anticipates this.

Question 4 - Do you have any suggestions for further development for future presentation of this project?

Need to have a session to show how it can be used. Debugging and anticipating problems. Biggest hassle was, couldn't get it to work and didn't have the experience to work it out, caused frustration. Nice if 
had a challenge to do more than simple sensing. Intro to Python is good - something physical.

Benefit from clearer description of what looking for. Spent too long on big ideas, but quickly discovered less ambition was best. Intro to Pi, checking how to use Python. Could have used Scratch, but wanted to use Python. Weren't quite set up right, stumped us for a while and some sensors just didn't work.

\section{ANALYSIS OF DATA}

The data raises a number of issues which are related to the metaanalysis within the literature review and seem to be a common feature within CS pedagogy. Firstly, taking into consideration the literature emanating from CS development with regards to the 'great principles of computing', namely 'computational structure', referred to as 'mechanics' and 'principles of design' [19], both the principle of mechanics and design have been tested here. Raspberry Pi and the coding systems Scratch and Python are generally regarded as being accessible programming tools that children can use with little if any requirement for face to face instruction. Therefore, it should be expected that CS graduates should be able to familiarise themselves with the equipment quite readily, which they did, after the trials of missing drivers were discovered. However, more worrying was that they claimed that the semantics of the coding was more crucial than the more sophisticated programming languages that they had studied as part of their degrees. This brings into question the use of this type of software for children's development in that it may cause difficulties later on in their programming structuring. Aside from this issue, the CT element was at risk in this study and it was touch and go whether the study would progress after just one hour. The initial fright of being set the task caused panic and confusion, which fits Dewey's [20] definition of a problem perfectly and although the trainees were able to reinterpret their goals, it took coaching for them to do so. Referring back to the literature, it would have been expected that PS and CT would have been a major part of their undergraduate development and so this should have been a relatively simple task for them to perform. However, as indicated in the brief references to soft skill literature, the techniques required for PS are not easily tied down and to some extent the ability to PS is experiential and epistemological. This may or may not have been developed in the trainee's degree course; however, the evidence here shows that they needed coaching through the process and required human support to overcome their initial shock. Furthermore, communication and social interaction play important parts in PS and although the trainees worked well together, they found it extremely difficult to liaise with trainees outside of their subject. This is a common phenomenon at this Northern England HEI and it is something that the university is working at to resolve. However, presently whatever methods used to try to get the subject specialisms mixing, they always find a way to polarise back to their specialisms. Although this observation is common throughout the specialisms, this academic during recruitment work in teacher training has found CS undergraduates in general more difficult to engage and it is noticeable that STEM trainees do not ordinarily socialise with $\mathrm{PE}$ or A\&D, who are generally more social interactive personalities. This is a generalised viewpoint, but observation over many years of training teachers can justify this comment. This must be addressed, especially for those wanting to enter professions requiring extensive communication and human interaction, such as teaching.

Turning next to the issues arising for ITT, not just in relation to CS but in general, this experiment has highlighted the need for trainees to be able to practise their subject specialism, before teaching practice begins with real children. Allowing trainees to develop their soft skills away from the pressure of performance monitoring and the myriad of the Teachers' Standards, notwithstanding the pressure of engaging the children, is crucial for their self-esteem and reflective capacity. ITT in its present form is becoming more weighted towards on the job training in schools, where more time is allocated to being with the children in the classroom. Although initially liked by the trainees, after all this is what they have signed up for, they quickly realise that the maelstrom of the classroom is not the ideal place to develop themselves as a teacher of their subject, there is no time to prepare or time to reflect, they are always under the scrutiny of the school mentor and more importantly from the children. On the other hand, during university time, they have the opportunity to communicate with many more trainees from a wide variety of specialisms who are having a wider array of experiences, which they are encouraged to share. The time allocated to this task and the support mechanisms in place cannot be replicated in school. The trainees agreed that they learnt a great deal, not only technically, but their PS skills were further developed too. This is crucial if they are going to perform as qualified teachers in this field, because when they are in school responsible for curriculum development, they will be expected to be able to realise and develop projects, using constantly updating DT and CS to keep abreast of innovation as well as development in pedagogy generally. School teaching is not an easy vocation, it requires dedication, resilience and tenacity, subject knowledge is crucial, but so is social interaction and all of the soft skills required for PS which erupt at a moment's notice in any school environment. It is for this reason that ITT needs to be delivered carefully, so that potential teachers are nurtured into position and not thrown in at the deep end and left to sink or swim.

\section{CONCLUSIONS AND FURTHER RESEARCH}

A post-graduate course should challenge a graduate's knowledge and ability in their specialist subject, in order for them to demonstrate mastery in their subject and to highlight areas of need and future development. This project provided sufficient challenge to the CS graduates as well as raising some common issues surrounding 'soft skills and 'people skills' [21] associated with STEM based students. Furthermore, ITI issues 
have also been highlighted and some conclusions can be drawn from the result of this study.

The Government's overhaul of the National Curriculum in England in 2014 [22] has resulted in a prescriptive body of knowledge that the implementing Secretary of Education claimed 'provides pupils with an introduction to the essential knowledge that they need to be educated citizens. It introduces pupils to the best that has been thought and said'. Coupled with stricter and tighter monitoring of pupil performance has created tensions and stress in schools unparalleled in previous years. There is recognised to be a recruitment crisis in teaching, especially for STEM based subjects and more qualified teachers are presently leaving the profession sooner than ever before. This is exacerbated by the confusing array of ITT routes, which not only is wasting finance in marketing ploys, but also creating unnecessary competitive behaviours between providers. Some routes market themselves as apprenticeships to teaching, claiming that the best way to become a teacher is by spending more time in the classroom. Practicing teachers and schools' core business is educating children, with the best will in the world, unless teachers are removed from the classroom, practising teachers are extremely busy doing what they do best, i.e. looking after the needs of children. They do not have the time or expertise to take on an apprentice and nurture their needs at the same time. Furthermore, is it good practice to remove 'good' teachers from their classroom environment in order to develop trainee teachers? Invariably, the scenario follows that ITT's on such routes spend more and more time in the classroom 'learning by doing'. Is this really the best way to develop a professional, by leaving to chance what they might experience in any given classroom, school or Multi Academy Trust? At this Northern England HEI it is believed that the traditional route to qualified teacher status, through a mixed approach of university offsite reflection and school on site coaching and development is preferable. To this end there is an endeavour to give the trainees as much exposure to collaboration and sharing experiences as possible. Not only can they learn from others' experiences multiplicatively, but they are also able to develop the soft-skills necessary to solve the multiple problems that they will face in their daily working lives as a teacher.

This project has highlighted the need for time for soft skill PS techniques to be developed, but it also builds on previous evidence that soft skills should be an important element of every aspect of education, from pre-school to post graduate level. Countries such as Malaysia have realised that an education system based on results does not provide the basis for a population to advance in the modern technical world [21], so their Government has imposed soft skill curricula on their HEI's. The development in England of a results based curriculum and further announcement of Grammar selection based on ability, could be moving this society into similar difficulties in the future.

\section{A. Future research development}

- There is a need to develop curricula at all levels to contain soft skill experience, more research must be done to alleviate the deficiency of graduates' difficulties in this area.

- There is a need to develop cross-curricula activities, particularly in STEM related subjects, in order to expose more children to the benefits of studying STEM at an early age and beyond, this should be developed as part of ITT.

- The introduction of the CS curriculum in England has a chance of stalling, due to a lack of teachers to teach it and low recruitment rates into the profession, similar to the original intent of the Design and Technology agenda in 1988, more research must be done to ensure this does not happen.

- $\quad$ ITT is at a cross road and is currently in the hands of politicians, who through a genuine experiential lack of understanding are easily swayed by consultation, more research needs to be done to show the impact this is having on teacher recruitment and service longevity.

- The issues raised by the participants in this project will be analysed further, so that future participants will not be constrained in a similar manner.

\section{REFERENCES}

[1] Department for Education Computing programmes of study: Key Stages 3 and 4, National Curriculum in England National, pp 1-3, 2013.

[2] J. Voogt, and G. Knezek, Guest Editorial: Technology enhanced quality education for all - outcomes from EDUsummIT 2015, Educational Technology and Society, 19 (3), 1-4, 2015.

[3] W. Ahmed, A. Minnaert, G. Werf and H. Kuyper, "Perceived social support and early adolescents' achievement: The mediational roles of motivational beliefs and emotions", Journal of Youth Adolescence, 39:36-46, 2010.

[4] J.P. Gee (2004), "Situated language and learning: A critique of traditional schooling", New York: Routledge, 2004.

[5] Tang and Tan in T. Ngang, T. Chan and D. Uma, "Critical issues of soft skills development in teaching professional training: Educators' perspectives", $6^{\text {th }}$ World conference on Psychology Counselling and Guidance, 14-16 May 2015, Procedia - Social and Behavioural Sciences, 205, 128-133, 2015.

[6] Y. Ulusoy, H. Turan, B. Tanriverdi and H. Kolayis, "Comparison of perceived problem solving skills of trainee students graduated from different", Procedia - Social and Behavioural Sciences, 46, 2099-2103, 2012.

[7] G. Erdamar and G. Alpan, "Examining the epistemological beliefs and problem solving skills of preservice teachers during teaching practice", Teaching in Higher Education, Vol. 18, No. 2, 129-143, 2013.

[8] A. Zendler, O. McClung and D. Klaudt (2012), "A cross-cultural comparison of concepts in computer science education: The US-Germany experience", The International Journal of Information and Learning Technology, Vol. 32, No. 4, 235-256, 2012.

[9] Turer in M. Dogru, "The application of problem solving method on science teacher trainees on the solution of the environmental problems", Journal of Environmental and Science Education, 3 (1), 9-18, 2008.

10] E. Arslan, "Analysis of communication skill and interpersonal problem solving in preschool trainees", Social Behaviour and Personality, 38 (4), 523$530,2010$.

[11] M. Karami, Z. Karami and M. Attaran, "Integrating problem-based learning with ICT for developing trainee teachers' content knowledge and teaching skill", International Journal of Education and Development using Information and Communication Technology, Vol. 9, Issue 1, 36-49, 2013. 
[12] S. Papert, "Mindstorms: Children, computers and powerful ideas", New York: Basic Books, 1990.

[13] S. Papert, "Situating constructivism". In I. Harel and S. Papert (Eds.), Constructionism, Norwood: Ablex, 1991.

[14] E. Jarvinen and A. Rasinen, "Implementing technology education in Finnish general education schools: Studying the cross-curricular theme 'Human being and technology", International Journal of Technology Design Education, 25: 67-84, 2015.

[15] S. Fincher, "What are we doing when we teach computing in schools?" Communications of the ACM, May 2015, Vol. 58, No. 5, 2015.

[16] Z. Unlu and I. Dokme, " $7^{\text {th }}$ grade students' views on combining the use of computer simulations and laboratory activities in science teaching", Procedia Social and Behavioural Sciences, 191, 1173-1177, 2015.

[17] V. Cerf, "Computer science in the curriculum", Communication of the ACM, March 2016, Vol.59, No. 3, 2016.

[18] D. Franklin, "Putting the computer science in computing education research", Communication of the ACM, February 2015, Vol. 58, No. 2, 2015.

[19] P. Denning, "The profession of IT: Great principles of computing", Communications of the ACM, Vol. 46, No. 11, 2003.

[20] J. Dewey, "How we think", New York: Prometheus Books, 1991.

[21] R. Shakir, "Soft skills at the Malaysian institutes of higher learning", Asia Pacific Education Revue, 10, 309-315, 2009.

[22] Department for Education, The national Curriculum in England, Framework document, July 2014. 